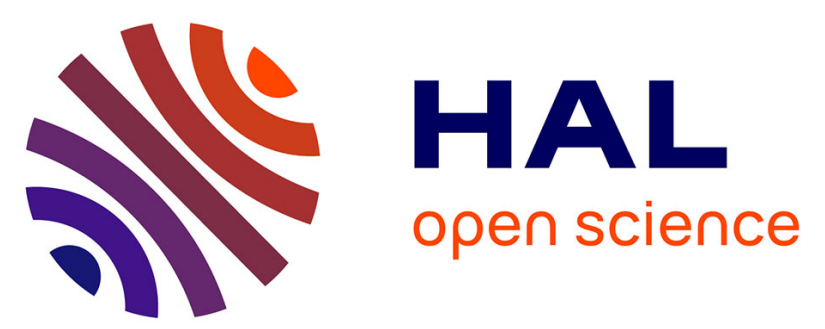

\title{
Trends in prenatal diagnosis, pregnancy termination, and perinatal mortality of newborns with congenital heart disease in France, 1983-2000: a population-based evaluation.
}

Babak Khoshnood, Catherine de Vigan, Véronique Vodovar, Janine Goujard, Anne Lhomme, Damien Bonnet, François Goffinet

\section{To cite this version:}

Babak Khoshnood, Catherine de Vigan, Véronique Vodovar, Janine Goujard, Anne Lhomme, et al.. Trends in prenatal diagnosis, pregnancy termination, and perinatal mortality of newborns with congenital heart disease in France, 1983-2000: a population-based evaluation.. Pediatrics, 2005, 115 (1), pp.95-101. 10.1542/peds.2004-0516 . inserm-00108256

\section{HAL Id: inserm-00108256 https://www.hal.inserm.fr/inserm-00108256}

Submitted on 30 Nov 2007

HAL is a multi-disciplinary open access archive for the deposit and dissemination of scientific research documents, whether they are published or not. The documents may come from teaching and research institutions in France or abroad, or from public or private research centers.
L'archive ouverte pluridisciplinaire HAL, est destinée au dépôt et à la diffusion de documents scientifiques de niveau recherche, publiés ou non, émanant des établissements d'enseignement et de recherche français ou étrangers, des laboratoires publics ou privés. 
Trends in prenatal diagnosis, pregnancy termination and perinatal mortality of newborns with congenital heart disease in France, 1983 - 2000: A population-based evaluation

Published : Pediatrics, January 2005 (awaiting reprints - available upon request)

Babak Khoshnood $^{\#, *}, \mathrm{MD}, \mathrm{PhD}$, Catherine De Vigan", MD, Véronique Vodovar ${ }^{\#}$, RN, Janine Goujard $^{\#}$, MD, Anne Lhomme", MS, Damien Bonnet ${ }^{\text {" }}$, MD, François Goffinet ${ }^{\#}$, MD, MPH

\# Paris Registry of Congenital Malformations, Epidemiological Research Unit on Perinatal and Women's Health, INSERM U149, France

"Service de Cardiologie Pédiatrique, Hôpital Necker-Enfants Malades, Paris, France

* Support by the INSERM program of visiting fellowships for foreign researchers (poste vert) is gratefully acknowledged.

Correspondence, proofs and reprint requests to:

Babak Khoshnood, INSERM U149, 16 Avenue Paul Vaillant Couturier, 94807 VILLEJUIF Cedex, France

Tel: $\quad$ (33 1) 45595009

Fax: $\quad$ (33 1) 45595089

Email: khoshnood@vjf.inserm.fr

Word counts: Abstract: 276, Text: 3,585, References: 863.

Keywords: congenital heart disease, prenatal diagnosis, France, mortality Abbreviations: CHD: Congenital Heart Disease 
Abstract

Objective: 1) Examine population-based overall and malformation-specific trends in the prenatal diagnosis, pregnancy termination and perinatal mortality for congenital heart disease(CHD) during a period of rapid progress in prenatal diagnosis and medical management of CHD;2) Explore the impact of prenatal diagnosis on early neonatal mortality for specific(isolated) cardiac malformations.

Methods: 1982 cases of CHD, which were not associated with a known chromosomal anomaly, were obtained from the Paris Registry of Congenital Malformations. Main outcome measures were trends in the proportions diagnosed and terminated prior to birth, stillbirth and early $(<1$ day, one-week) neonatal mortality for: i) all cases, ii) all cases excluding isolated ventricular septal defects, and iii) malformation-specific trends for transposition of great arteries(TGA), hypoplastic left heart syndrome(HLHS), coarctation of aorta, and tetralogy of Fallot. Analyses included cusum and binomial regression models for analysis of the trends during 1983-2000. Results: Prenatal diagnosis rates for CHD increased from 23.0\% (95\%CI, 19.0-27.4) in 19831988 to $47.3 \%$ (95\%CI, 43.8-50.8) in 1995-2000. Termination rates increased between 1983$1989(9.9 \%, 95 \% \mathrm{CI}, 7.2-13.2)$ and 1989-1994 (14.7\%, 95\%CI, 12.3-17.4) but appeared to remain stable thereafter. Other than for HLHS, pregnancy termination was exceptional for the other three specific malformations examined. Early neonatal mortality decreased to less than a third in the period 1995-2000 as compared with 1983-1989 (RR, first week mortality, 0.31, 95\%CI, 0.180.53). First week mortality was significantly lower for cases of TGA diagnosed prior to birth (Risk Difference, 15.4\%, 95\% CI, 4.0-26.7).

Conclusions: Progress in clinical management, together with policies for increased access to prenatal diagnosis has resulted in both a substantial increase in the prenatal diagnosis, and considerable reductions in early neonatal mortality of CHD in the Parisian population. 
Introduction

Congenital heart disease (CHD) is the most common congenital anomaly ${ }^{1,2}$ and a major cause of mortality and morbidity in the perinatal period ${ }^{3}$. The reported prevalence of CHD is subject to a great deal of variation across different populations and registries, presumably for the most part due to differences in the inclusion of milder anomalies ${ }^{2,4}$. On the other hand, the reported prevalence of severe CHD appears to be fairly constant across different populations and is approximately 3.0 per 1,000 live births. Differences exist however in the rates of prenatal diagnosis and termination of CHD across populations ${ }^{5,6}$ and over time $e^{4,7,8}$, which can have an impact on the livebirth prevalence of the more severe cases of $\mathrm{CHD}^{9}$, particularly for hypoplastic left heart syndrome ${ }^{10}$.

France pursues an active policy of antenatal surveillance, particularly for prenatal diagnosis of congenital anomalies ${ }^{11,12}$. Prenatal diagnosis of structural CHD with transabdominal ultrasonography began in the early 1980 s and became widespread in the late $1980 \mathrm{~s}^{13}$. Detection rates for structural heart defects have been shown to be higher in France than other European countries $^{5,6,14}$ or the United States ${ }^{7}$. However, the impact of prenatal diagnosis on the outcomes of newborns with structural heart disease has been difficult to evaluate ${ }^{15}$, mostly due to problems related to selection bias as cases that are more likely to be diagnosed prenatally tend to be the more severe cases. Hence, not surprisingly previous studies have often found overall poorer outcomes in cases of CHD that are diagnosed prenatally ${ }^{7,16-18}$. The impact of prenatal diagnosis has been shown to vary considerably across different malformations with improved outcomes reported for prenatally diagnosed cases of coarctation of aorta and transposition of great $\operatorname{arteries}^{17,19-23}$. Nevertheless, even findings from the studies that have assessed the same set of anomalies have not been consistent ${ }^{19-22}$. Moreover, few population-based studies ${ }^{7,18,24}$ have 
evaluated the impact of prenatal diagnosis on neonatal outcomes and none have examined the entire period that spans the introduction of screening in the 1980s until the most recent period.

In this study, we examine overall and malformation-specific trends in the prenatal diagnosis, pregnancy termination and perinatal mortality due to congenital heart disease using population-based data from the Paris Registry of Congenital Malformations for the years 1983 to 2000. We also assess trends in the timing of prenatal diagnosis and pregnancy termination. In addition, we explore the impact of prenatal diagnosis on early neonatal mortality for hypoplastic left heart syndrome and transposition of great arteries for which previous hospital-based studies have reported conflicting results ${ }^{19-22}$.

Materials and Methods

Data

2440 cases of congenital heart disease were obtained from the Paris Registry of Congenital Malformations for the years 1983 - 2000. The base study population corresponded to births and terminations of pregnancy to women who were residents of Paris and gave birth or had a termination of pregnancy in a Parisian maternity during the period 1983-2000 (Total number of births $=452,867)$. Data for the Registry are collected from multiple sources of information, including maternity units, neonatology services, cytogenetic and pathology services, in order to allow high case ascertainment for malformations and chromosomal abnormalities. Registration is essentially complete for cases identified during the initial hospitalization for delivery or for those identified in the post-mortem examination. The registration, including mortality outcomes are not complete however for late diagnoses or for mortality outcomes beyond the early (first week) neonatal period. 
The diagnosis for each case was either based on an evaluation by a pediatric cardiologist as documented in the medical chart or on post-mortem examination. Cases were classified following the International Classification of Disease 9.0 and included i) bulbus cordis anomalies and anomalies of cardiac septal closure (ICD9 code 745), ii) other congenital anomalies of the heart (ICD9 code 746) and iii) other congenital anomalies of circulatory systems (ICD9 code 747). Cardiac anomalies associated with a known chromosomal anomaly comprised $18.1 \%(\mathrm{~N}=$ 458) of cases. These cases were excluded from further analyses. Hence, the study population comprised 1982 cases of congenital heart disease. In addition, 13 cases $(0.7 \%)$ had missing information on prenatal diagnosis and were excluded from the analyses of trends in prenatal diagnosis.

Main outcome measures for the study were trends in the proportion diagnosed and/or terminated prior to birth, perinatal (stillbirth plus early neonatal mortality) and early ( $<24$ hours, one-week) neonatal mortality of cases not associated with a chromosomal anomaly. Trends were examined for: i) all cases, ii) all cases excluding isolated ventricular septal defects, and iii) malformation-specific trends for isolated cases of transposition of great arteries, hypoplastic left heart syndrome, coarctation of aorta, and tetralogy of Fallot. We also assessed timing of prenatal diagnosis and pregnancy termination by examining trends in the median gestational age at diagnosis and at termination.

Analyses that excluded isolated ventricular septal defects, and the malformation-specific analyses were undertaken in order to: a) partially control for the potential selection bias due to increasing diagnosis of less severe cases over time, and b) examine heterogeneities in prenatal diagnosis and outcomes for four major anomalies. In order to assess the impact of associated malformations on study outcomes, we examined the prenatal diagnosis, pregnancy termination and perinatal mortality of the isolated cases of CHD for the most recent period (1995-2000). For 
this analysis, isolated cases of CHD were defined as those that were not associated with another major, non-cardiac malformation. During this period, approximately $17 \%$ of cases (among those without a known chromosomal anomaly) were associated with at least one other major noncardiac malformation.

Statistical Analysis

We report proportions with $95 \%$ binomial exact confidence intervals. We used cusums for nonparametric analysis of time trends in binary variables ${ }^{25}$. This technique allows detection of significant monotonic (always increasing / decreasing) and nonmonotonic (e.g., quadratic) trends. Inverted U-shaped curves of cusums over time suggest a monotonically increasing trend in proportions over time, whereas U-shaped curves suggest a monotonically decreasing trend. We also used binomial regression models ${ }^{26}$ for analysis of maternal age-adjusted trends in the study outcomes. Maternal age was considered a potential confounding variable in the analyses of trends since: i) there has been a consistent trend towards delayed childbearing in the Parisian population, and ii) the prenatal surveillance of older women might be different from their younger counterparts; as older women are at higher risk for adverse pregnancy outcomes including congenital anomalies. The Kruskal-Wallis test was done to test the statistical significance of trends in the timing of prenatal diagnosis and pregnancy termination.

Binomial regression was also used for analysis of time period-adjusted effect of prenatal diagnosis on neonatal mortality of infants born with transposition of great arteries. This was done to control for the potentially confounding effect of time. Such confounding could arise since: i) the rate of prenatal diagnosis of transposition of great arteries has increased over time; ii) the spectrum of severity of cases diagnosed might have changed over time; and iii) the clinical management (medical as well as surgical) of infants born with transposition of great arteries has 
in all likelihood improved over time (in ways that might not be directly or indirectly related to prenatal diagnosis of the anomaly). 
Results

\section{Prenatal diagnosis}

The proportion of CHD cases diagnosed prenatally increased from $23.0 \%$ (95\% CI, 19.0 - 27.4) in 1983 - 1988 to $47.3 \%$ (95\% CI, 43.8 - 50.8) in 1995 - 2000 (Table 1). Cusum analysis suggested a monotonically increasing time trend in the proportion of cases diagnosed prior to birth (Figure 1, $\mathrm{p}<0.001$ ). This was true both for all cases and for all cases excluding isolated ventricular septal defects (Table 1). Compared with the period 1983-1988, there was an increase of $34 \%$ in maternal age-adjusted probability of prenatal diagnosis for CHD in 1989 - 1994 (Ageadjusted Risk Ratio (RR) 1.34, 95\% CI, 1.09 - 1.65), and a two-fold increase (Age-adjusted RR $1.99,95 \%$ CI, $1.64-2.41$ ) in the prenatal diagnosis of CHD in 1995 - 2000 (Table 2). Analysis of prenatal diagnosis rates for isolated cases only during the most recent period (1995 - 2000) suggested essentially the same prenatal diagnosis rates; the proportion of isolated cases with a prenatal diagnosis was 45.4\% (95\% CI, 41.4-49.5) as compared with 47.3\% (95\% CI, 43.8-50.8) for all cases.

Trends in prenatal diagnosis differed substantially across the four specific malformations examined (Table 3). However, for all four malformations there were significant increases in the proportion of cases diagnosed prenatally over time. By the most recent period, approximately $3 / 4$ of the cases of the transposition of great arteries $(72.5 \%, 95 \% \mathrm{CI}, 56.1-85.4), 90 \%$ of the cases of hypoplastic left heart syndrome $(88.9 \%, 95 \%$ CI, $70.8-97.6), 40 \%$ of the cases of coarctation of aorta $(42.4 \%, 95 \% \mathrm{CI}, 25.5-60.8)$ and $70 \%$ of cases of tetralogy of Fallot $(69.7 \%, 95 \% \mathrm{CI}$, $51.3-84.4)$ were diagnosed prenatally.

Gestational age at prenatal diagnosis decreased significantly over time (Kruskal-Wallis test, $\mathrm{p}=0.001$ ). The median gestational age at diagnosis was 27 weeks during the period $1983-$ 1988, 25 weeks in 1989 - 1994 and 23 weeks in 1995 - 2000. Gestational age at diagnosis also 
decreased significantly for cases that were terminated; median gestational age at diagnosis was 24 weeks in 1983 - 1988, 23 weeks in $1989-1995$ and 22 weeks in $1995-2000$ ( $p=0.0005)$. In particular, timing of prenatal diagnosis decreased significantly for cases of hypoplastic left heart syndrome; 24 weeks, 23 weeks, and 21 weeks of gestation for the three periods, respectively ( $\mathrm{p}=$ 0.04).

Pregnancy termination

The proportion of cases of CHD that were terminated prior to birth increased between 1983 - 1988 and 1989 - 1994 but appeared to remain stable thereafter (Tables 1 and 2). Overall, approximately $15 \%$ of the cases were terminated in $1995-2000(15.4 \%, 95 \%$ CI, $13.0-18.1)$. The pregnancy termination rates for the isolated cases appeared to be somewhat lower (12.2\%, 95\% CI, $9.7-15.1$ ) during this same period. This difference did not reach statistical significance however.

During the most recent period, almost half of the cases terminated (45.4\%, 95\% CI, $33.5-$ 57.3) were accounted for by "complex" CHD involving at least two distinct anomalies (ICD 9 codes) . During this same period, the most frequent cases of CHD terminated involved hypoplastic left heart syndrome, univentricular heart, and to a lesser extent, pulmonary valve abnormalities (e.g., pulmonary atresia), atrioventricular septal defect, and congenital aortic valve stenosis.

Other than for hypoplastic left heart syndrome, termination of pregnancy was exceptional in the case of the other three specific malformations examined (Table 3). In contrast, more than $60 \%$ of the cases of hypoplastic left heart syndrome were terminated in the more recent periods, $72.4 \%(95 \%$ CI, $52.8-87.3)$ in $1989-1994$, and 63.0\% (95\% CI, 42.4 - 80.6) in $1995-2000$. 
Median gestational age at termination did not change significantly over time; median age at termination was 25 weeks in $1983-1988$ and $1989-1994$, and 24 weeks in $1995-2000(\mathrm{p}=$ 0.18). Timing of pregnancy termination did not appreciably change for the cases of hypoplastic left heart syndrome either.

\section{Perinatal mortality}

Perinatal mortality decreased substantially for congenital heart disease over time to almost a third in 1995 - 2000 (Maternal age-adjusted RR, 0.38, 95\% CI, $0.27-0.57$ ) as compared with 1983 - 1988 (Table 2). Cusum analysis suggested a monotonically decreasing trend over time (Figure 2, $\mathrm{p}<0.001$ ). Stillbirth, first day and first week neonatal mortality all decreased substantially over time; however, the trends appeared to be greater for neonatal mortality than for stillbirth (Table 1). Stillbirth rate decreased by about one half (Maternal age-adjusted RR, 0.49, $95 \% \mathrm{CI}, 0.27-0.87)$, whereas early neonatal mortality of newborns with congenital heart disease decreased to less than a third in the period 1995-2000 as compared with 1983-1989 (Table 2); first day mortality, maternal age-adjusted RR 0.30, 95\%CI, $0.11-0.82$, and first week mortality, adjusted RR 0.31, 95\%CI, $0.18-0.53)$.

Analysis of mortality outcomes for isolated cases showed comparable perinatal and neonatal mortality rates. For example, the perinatal mortality rates for all cases was $6.4 \%$ (95\% CI, $4.7-8.5)$ during 1995 - 2000 as compared with 5.1\% (95\% CI, 3.4 - 7.4) for isolated cases. Similarly, the first week mortality was 3.3\% (95\% CI, $2.1-5.0)$ for all cases during $1995-2000$ as compared with $3.7 \%$ (95\% CI, $2.2-5.7)$ for the isolated cases. In general, as isolated cases accounted for the overwhelming majority $(>80 \%)$ of cases, their outcomes determined to a large extent the overall outcomes for the cases of CHD. 
There was a substantial decrease in perinatal mortality due to transposition of great arteries and hypoplastic left heart syndrome over time (Table 3); however, differences did not reach statistical significance for the latter $(p=0.10)$. For transposition of great arteries, first week neonatal mortality decreased from approximately $19 \%$ in $1983-1988(18.8 \%, 95 \%$ CI, 4.0 $-45.6)$ to about $3 \%(2.6 \%, 95 \% \mathrm{CI}, 0.1-13.5)$ in $1995-2000(\mathrm{p}=0.04)$. For coarctation of aorta and tetralogy of Fallot, the number of isolated cases was not sufficient to assess trends over time.

Finally, first week mortality was significantly lower for cases of transposition of great arteries diagnosed prior to birth (Fischer's Exact test, $\mathrm{p}=0.01$ ); the mortality rate was $15.4 \%$ for cases diagnosed after birth $(\mathrm{N}=39)$ as compared with $0 \%$ for cases diagnosed prior to birth $(\mathrm{N}=$ 39); Risk Difference, $15.4 \%$ (95\% CI, 4.0 - 26.7). This difference decreased slightly but remained statistically significant after adjustment for time period (Time period-adjusted Risk Difference, $12.8 \%, 95 \%$ CI, $0.002-25.3 \%$ ). On the other hand, we did not find any evidence for a significant impact of prenatal diagnosis on early neonatal mortality for hypoplastic left heart syndrome; the first week neonatal mortality rate was $69.2 \%$ for prenatally diagnosed cases $(\mathrm{N}=$ 13), and $73.9 \%$ for cases diagnosed postnatally $(\mathrm{N}=23)$. 


\section{Discussion}

In summary, we found substantial increases in prenatal diagnosis of congenital heart disease in the Parisian population over the study period. Currently, more than $50 \%$ of the cases of CHD that are not associated with a known chromosomal anomaly are likely to be diagnosed prenatally. Prenatal diagnosis occurred at a significantly earlier time over the study period, in particular for cases that were terminated. Trends varied substantially across different malformations examined. Our results suggest that almost $90 \%$ of the cases of hypoplastic left heart syndrome are diagnosed prenatally and $60 \%$ are terminated prior to birth. Overall, termination rates increased between 1983 - 1988 and 1989 - 1994 but appeared to remain stable thereafter. Timing of pregnancy termination did not appreciably change during the study period.

By the end of 1990s, perinatal mortality due to CHD decreased to about one-third its rate in the 1980s. This was particularly the case for the transposition of great arteries for which early neonatal mortality decreased to about one-sixth. Prenatal diagnosis of transposition of great arteries was associated with a substantially lower first week neonatal mortality. This effect of prenatal diagnosis remained significant after adjustment for time period. On the other hand, we did not find a significant effect for prenatal diagnosis on early neonatal mortality of hypoplastic left heart syndrome.

The interpretation of our results is subject to several caveats and limitations. One potential source of bias that might lead to overestimation of prenatal diagnosis rates relates to the possibility of incomplete case ascertainment. This might be particularly the case for infants born with CHD who had a late diagnosis or those that were undiagnosed. Some of the latter may comprise less severe cases that remain asymptomatic during the early neonatal period. It is important in general to distinguish sources of bias that concern baseline rates, e.g., incomplete case ascertainment because of limited registration that only includes early neonatal period, from 
sources of bias that might be related to trends over time. We are not aware of any reason to expect that case ascertainment in the postnatal period decreased over time. Hence, the time trends we observed are likely to reflect true increases in prenatal diagnosis of CHD.

Another important potential source of bias relates to the observed increase in number of CHD cases over time. There are four potential explanations for such trend: i) increased prenatal and early postnatal diagnosis of cases over time, and in particular increased diagnosis of less severe cases (e.g., isolated ventricular septal defects) as a result of progress in cardiac echography; ii) increased post-mortem diagnosis of anomalies as the Registry data suggest that post-mortem examinations for congenital anomalies have increased over time ${ }^{27}$; iii) referral bias, which we attempted to minimize by including only women who resided in Paris and gave birth at a Parisian maternity unites; and iv) increase in maternal age-related chromosomal anomalies (most importantly Trisomy 21) that are associated with congenital heart disease. To minimize the latter, we excluded all congenital heart defects that were associated with known chromosomal anomalies.

Perhaps the most important source of potential bias that could result in underestimation of mortality rates due to $\mathrm{CHD}$ over time relates to increased diagnosis and hence inclusion of less severe cases. Such selection bias could potentially explain all or part of the observed trends for lower perinatal mortality over time. We conducted the analyses that excluded isolated ventricular septal defects in order to partially control for such selection. Indeed, both the baseline outcomes and time trends did differ for the subset of CHD that excluded isolated ventricular septal defects. However, differences in trends for mortality with or without inclusion of isolated ventricular septal defects were most notable between 1983 - 1988 and 1989 - 1994. By the most recent period (1995 - 2000), trends in perinatal mortality were essentially the same for all CHD combined and the subset of CHD that excluded isolated ventricular septal defects. 
The absolute number of deaths due to CHD also decreased over time, further suggesting that increases in the registered cases of CHD (i.e., the denominators for mortality rates) do not entirely explain the observed decreases in mortality over time. Moreover, the malformationspecific trends are presumably less subject to selection bias due to inclusion of less severe cases over time. Therefore, for the four specific malformations examined, the severity of cases might not have changed substantially over time. In any case, our results regarding trends in mortality rates due to $\mathrm{CHD}$ cannot be considered as definitive as data limitations preclude a complete control for selection bias.

The observed decreases in perinatal mortality might have been in part related to the increases in pregnancy termination for severe cases of CHD. Indeed, termination rates significantly increased between 1983 - 1988 and 1989 - 1994. Nevertheless, while termination rates remained essentially stable between 1989 - 1994 and 1995 - 2000, perinatal mortality, and in particular early neonatal mortality continued to decrease, both overall and for the four specific malformations examined.

Our analyses of trends in perinatal mortality were limited to the early neonatal period (first week). While the Paris Registry includes data on mortality up to one year of age, the data beyond the first week is not collected systematically. In our analyses of available data for infant (i.e., up to one year of age) mortality, we found similar trends as those we report here for first week mortality (data available upon request). However, a full evaluation of the question of late neonatal and postneonatal mortality of infants born with CHD requires population-based data with complete assessment of mortality up to one year of age. In addition, we had limited power in assessing trends in perinatal mortality due to specific malformations, in particular for coarctation of aorta and tetralogy of Fallot. 
Our findings on the survival advantage of prenatally diagnosed cases of transposition of great arteries are consistent with those reported based on a large hospital-series by Bonnet and colleagues ${ }^{19}$ from a major pediatric cardiology center in Paris. Our results differ however from those of Kumar et $\mathrm{al}^{20}$. Potential explanations for these differences include: i) variations in case ascertainment, in particular, inclusion of deaths due to CHD not diagnosed during life, which was done in the study by Bonnet et al and in our study; ii) differences in case-mix not accounted for by our control for time period; and iii) clinical management, or other factors related to organization of services in the different populations studied.

In conclusion, progress in clinical management, together with policies for increased access to prenatal diagnosis has resulted in a substantial increase in the prenatal diagnosis, and a considerable reduction in perinatal mortality of infant with CHD in the Parisian population. This does not imply however that prenatal diagnosis generally confers a survival advantage to infants born with CHD. Findings from our study and the available evidence in the literature suggest that prenatal diagnosis might have improved the outcomes for certain anomalies. Nevertheless, much of the improvement in outcomes for CHD probably came about as a result of progress in postnatal medical and surgical care of newborns with CHD. At the same time, increased prenatal diagnosis of CHD has provided a greater opportunity for consultation between healthcare professionals and parents, and thereby the possibility for more informed decision-making for parents and their caregivers.

Our findings need to be corroborated and expanded upon using population-based data from a reasonably large cohort of newborns with CHD with sufficient follow-up and detailed assessment of diagnoses and outcomes. In addition, with the improvements in the survival of infants with CHD, it becomes increasingly important to evaluate the role of prognostic factors including that of prenatal diagnosis in determining the mortality, morbidity and in particular 
neurodevelopmental outcomes of infants with congenital heart disease $\mathrm{e}^{28}$. Heterogeneities in outcomes across different cardiac anomalies ${ }^{15,17,19-21,23}$ and for given anomalies at different centers $^{19,20,29,30}$, disparities in outcomes across socioeconomic groups ${ }^{31,32}$, and alternative strategies for antenatal screening of $\mathrm{CHD}^{33-35}$ also need to be further examined. 


\section{References}

(1) Hoffman JI. Incidence of congenital heart disease: II. Prenatal incidence. Pediatr Cardiol. $1995 ; 16: 155-165$.

(2) Hoffman JI, Kaplan S. The incidence of congenital heart disease. J Am Coll Cardiol. 2002; 39:1890-1900.

(3) Lee K, Khoshnood B, Chen L et al. Infant mortality from congenital malformations in the United States, 1970-1997. Obstet Gynecol. 2001; 98:620-627.

(4) Wren C, Richmond S, Donaldson L. Temporal variability in birth prevalence of cardiovascular malformations. Heart. 2000; 83:414-419.

(5) Garne E, Stoll C, Clementi M, Euroscan Group. Evaluation of prenatal diagnosis of congenital heart diseases by ultrasound: experience from 20 European registries. Ultrasound Obstet Gynecol. 2001; 17:386-391.

(6) Garne E, EUROCAT Working Group. Prenatal diagnosis of six major cardiac malformations in Europe--a population based study. Acta Obstet Gynecol Scand. 2001; 80:224-228.

(7) Montana E, Khoury MJ, Cragan JD et al. Trends and outcomes after prenatal diagnosis of congenital cardiac malformations by fetal echocardiography in a well defined birth population, Atlanta, Georgia, 1990-1994. J Am Coll Cardiol. 1996; 28:1805-1809.

(8) Bosi G, Garani G, Scorrano M, Calzolari E. Temporal variability in birth prevalence of congenital heart defects as recorded by a general birth defects registry. J Pediatr. 2003; 142:690-698.

(9) Bull C. Current and potential impact of fetal diagnosis on prevalence and spectrum of serious congenital heart disease at term in the UK. British Paediatric Cardiac Association. Lancet. 1999; 354:1242-1247.

(10) Allan LD, Cook A, Sullivan I, Sharland GK. Hypoplastic left heart syndrome: effects of fetal echocardiography on birth prevalence. Lancet. 1991; 337:959-961.

(11) Ayme S, Morichon N, Goujard J, Nisand I. Prenatal diagnosis in France. Eur J Hum Genet. 1997; 5(suppl 1):26-31.

(12) De Vigan C, Vodovar V, Verite V, Dehe S, Goujard J. Current French practices for prenatal diagnosis of trisomy 21: a population-based study in Paris, 1992-97. Prenat Diagn. 1999; 19:1113-1118.

(13) Friedman AH, Kleinman CS, Copel JA. Diagnosis of cardiac defects: where we've been, where we are and where we're going. Prenat Diagn. 2002; 22:280-284. 
(14) EUROCAT Working Group. EUROCAT Report 8: Surveillance of Congenital Anomalies in Europe, 1980-1999. 2002. Newtownabbey, Northern Ireland, University of Ulster.

(15) Sullivan ID. Prenatal diagnosis of structural heart disease: does it make a difference to survival? Arch Dis Child Fetal Neonatal Ed. 2002; 87:F19-F20.

(16) Sharland GK, Lockhart SM, Chita SK, Allan LD. Factors influencing the outcome of congenital heart disease detected prenatally. Arch Dis Child. 1991; 66:284-287.

(17) Copel JA, Tan AS, Kleinman CS. Does a prenatal diagnosis of congenital heart disease alter short-term outcome? Ultrasound Obstet Gynecol. 1997; 10:237-241.

(18) Levi S, Zhang WH, Alexander S, Viart P, Grandjean H. Short-term outcome of isolated and associated congenital heart defects in relation to antenatal ultrasound screening. Ultrasound Obstet Gynecol. 2003; 21:532-538.

(19) Bonnet D, Coltri A, Butera G et al. Detection of transposition of the great arteries in fetuses reduces neonatal morbidity and mortality. Circulation. 1999; 99:916-918.

(20) Kumar RK, Newburger JW, Gauvreau K, Kamenir SA, Hornberger LK. Comparison of outcome when hypoplastic left heart syndrome and transposition of the great arteries are diagnosed prenatally versus when diagnosis of these two conditions is made only postnatally. Am J Cardiol. 1999; 83:1649-1653.

(21) Mahle WT, Clancy RR, McGaurn SP, Goin JE, Clark BJ. Impact of prenatal diagnosis on survival and early neurologic morbidity in neonates with the hypoplastic left heart syndrome. Pediatrics. 2001; 107:1277-1282.

(22) Tworetzky W, McElhinney DB, Reddy VM et al. Improved surgical outcome after fetal diagnosis of hypoplastic left heart syndrome. Circulation. 2001; 103:1269-1273.

(23) Franklin O, Burch M, Manning N et al. Prenatal diagnosis of coarctation of the aorta improves survival and reduces morbidity. Heart. 2002; 87:67-69.

(24) De Vigan C, Goujard J, Vodovar V, Uzan S. Management of the fetus with a correctable malformation in Paris maternity units: evolution 1985-1994. Fetal Diagn Ther. 1997; $12: 216-220$.

(25) Royston P. The use of cusums and other techniques in modelling continuous covariates in logistic regression. Stat Med. 1992; 11:1115-1129.

(26) Robbins AS, Chao SY, Fonseca VP. What's the relative risk? A method to directly estimate risk ratios in cohort studies of common outcomes. Ann Epidemiol. 2002; 12:452454.

(27) De Vigan C, Lemaire I, Vodovar V, Khoshnood B, Goujard J, Goffinet F. Surveillance épidémiologique et diagnostic prénatal des malformations, évolution sur 20 ans, 19812000. 2003. Registre des malformations congénitales de Paris. 
(28) Wernovsky G, Newburger J. Neurologic and developmental morbidity in children with complex congenital heart disease. J Pediatr. 2003; 142:6-8.

(29) Jenkins KJ, Gauvreau K. Center-specific differences in mortality: preliminary analyses using the Risk Adjustment in Congenital Heart Surgery (RACHS-1) method. J Thorac Cardiovasc Surg. 2002; 124:97-104.

(30) Spiegelhalter D. Ranking institutions. J Thorac Cardiovasc Surg. 2003; 125:1171-1173.

(31) DeMone JA, Gonzalez PC, Gauvreau K, Piercey GE, Jenkins KJ. Risk of death for Medicaid recipients undergoing congenital heart surgery. Pediatr Cardiol. 2003; 24:97102.

(32) Gonzalez PC, Gauvreau K, DeMone JA, Piercey GE, Jenkins KJ. Regional racial and ethnic differences in mortality for congenital heart surgery in children may reflect unequal access to care. Pediatr Cardiol 2003; 24(2):103-108.

(33) Buskens E, Steyerberg EW, Hess J, Wladimiroff JW, Grobbee DE. Routine prenatal screening for congenital heart disease: what can be expected? A decision-analytic approach. Am J Public Health 1997; 87(6):962-967.

(34) Waitzman NJ, Romano PS. Reduced costs of congenital anomalies from fetal ultrasound: are they sufficient to justify routine screening in the United States? Ann N Y Acad Sci 1998; 847:141-153.

(35) Allan LD. Cardiac anatomy screening: what is the best time for screening in pregnancy? Curr Opin Obstet Gynecol 2003; 15(2):143-146. 
Table 1 - Prenatal diagnosis, pregnancy termination, perinatal and early neonatal mortality for congenital heart disease ${ }^{\text {t }}$ - Paris Registry of Congenital Malformations, 1983-2000

\begin{tabular}{|c|c|c|c|c|c|c|c|c|c|c|}
\hline \multirow[b]{2}{*}{ Prenatal Diagnosis } & \multicolumn{3}{|c|}{$1983-1988$} & \multicolumn{3}{|c|}{$1989-1994$} & \multicolumn{3}{|c|}{$1995-2000$} & \multirow[b]{2}{*}{$p^{\xi \xi}$} \\
\hline & $\mathrm{N}^{\#}$ & $\%$ & $95 \%$ CI* & $\mathrm{N}$ & $\%$ & $95 \% \mathrm{CI}^{*}$ & $\mathrm{~N}$ & $\%$ & $95 \% \mathrm{CI}^{*}$ & \\
\hline All & 409 & 23.0 & $19.0-27.4$ & 755 & 31.7 & $28.3-35.1$ & 805 & 47.3 & $43.8-50.8$ & $<0.001$ \\
\hline All except VSD** & 297 & 31.0 & $25.8-36.6$ & 480 & 47.5 & $43.0-52.1$ & 567 & 61.4 & $57.2-65.4$ & $<0.001$ \\
\hline \multicolumn{11}{|l|}{ Pregnancy Termination } \\
\hline A11 & 415 & 9.9 & $7.2-13.2$ & 755 & 14.7 & $12.3-17.4$ & 812 & 15.4 & $13.0-18.1$ & 0.037 \\
\hline All except VSD** & 303 & 13.5 & $9.9-17.9$ & 480 & 23.1 & $19.4-27.2$ & 574 & 21.8 & $18.5-25.4$ & 0.010 \\
\hline \multicolumn{11}{|l|}{ Stillbirth } \\
\hline All & 374 & 7.0 & $4.6-10.0$ & 644 & 4.0 & $2.7-5.9$ & 687 & 3.2 & $2.0-4.8$ & 0.028 \\
\hline All except VSD** & 262 & 9.2 & $6.0-13.3$ & 369 & 6.8 & $4.4-9.8$ & 449 & 4.5 & $2.7-6.8$ & 0.021 \\
\hline \multicolumn{11}{|l|}{ First Day Mortality } \\
\hline All & 348 & 2.9 & $1.4-5.2$ & 618 & 1.1 & $0.5-2.3$ & 665 & 1.1 & $0.4-2.2$ & 0.075 \\
\hline All except VSD** & 238 & 4.2 & $2.0-7.6$ & 344 & 2.0 & $0.8-4.1$ & 429 & 1.6 & $0.7-3.3$ & 0.132 \\
\hline \multicolumn{11}{|l|}{ First W eek Mortality } \\
\hline All & 348 & 10.1 & $7.1-13.7$ & 618 & 4.9 & $3.3-6.9$ & 665 & 3.3 & $2.1-5.0$ & $<0.001$ \\
\hline All except VSD** & 238 & 14.7 & $10.5-19.9$ & 344 & 8.7 & $6.0-12.2$ & 429 & 4.9 & $3.1-7.4$ & $<0.001$ \\
\hline \multicolumn{11}{|l|}{ Perinatal Mortality } \\
\hline All & 374 & 16.3 & $12.7-20.5$ & 644 & 8.7 & $6.6-11.1$ & 687 & 6.4 & $4.7-8.5$ & $<0.001$ \\
\hline All except VSD** & 262 & 22.5 & $17.6-28.1$ & 369 & 14.9 & $11.4-19.0$ & 449 & 9.1 & $6.6-12.2$ & $<0.001$ \\
\hline
\end{tabular}

* $95 \%$ binomial exact confidence interval

Cases with chromosomal anomalies were excluded.

\# For prenatal diagnosis and pregnancy terminations, the denominators $(\mathrm{N})$ were the total number of cases (stillbirths + live births + terminations of pregnancy) with congenital heart disease. For stillbirth and perinatal mortality, the denominator was stillbirths + live births, and for neonatal mortality, the denominator was live births.

**Isolated ventricular septal defects

t? test of significance for cusum linear annual trend 
Table 2 - Maternal age-adjusted trends in prenatal diagnosis, pregnancy termination, perinatal and early neonatal mortality for congenital heart disease

$$
1983-1988
$$

Prenatal Diagnosis

All except VSD**

$\begin{array}{cc}\text { Adjusted RR* } & 95 \% \text { CI } \\ 1.0 & \text { Reference } \\ 1.0 & \text { Reference }\end{array}$

Pregnancy Termination

All except VSD**

$\begin{array}{ll}1.0 & \text { Reference } \\ 1.0 & \text { Reference }\end{array}$

Stillbirth

All except VSD**

First Day Mortality

$\begin{array}{lll}\text { All } & 1.0 & \text { Reference } \\ \text { All except VSD** } & 1.0 & \text { Reference }\end{array}$

First W eek Mortality

$\begin{array}{lll}\text { All } & 1.0 & \text { Reference } \\ \text { All except VSD** } & 1.0 & \text { Reference }\end{array}$

Perinatal Mortality

\begin{tabular}{lll} 
All & 1.0 & Reference \\
All except VSD** & 1.0 & Reference \\
\hline
\end{tabular}

* Maternal age-adjusted risk ratio

${ }^{\mathrm{B}}$ Cases with chromosomal anomalies were excluded.

**Isolated ventricular septal defects

$$
1989-1994
$$

$\begin{array}{cc}\text { Adjusted RR* } & 95 \% \text { CI } \\ 1.34 & 1.09-1.65 \\ 1.49 & 1.23-1.81\end{array}$

\subsection{7}

1.70
$1.05-2.06$
$1.22-2.36$

\subsection{7}

0.73
$0.34-0.97$
$0.43-1.26$

\begin{abstract}
0.37
\end{abstract}
0.44

$0.14-0.95$

$0.17-1.14$

0.47

0.58

\begin{abstract}
$0.29-0.76$
\end{abstract}
$0.37-0.93$

0.53

0.66

$0.47-0.92$
$1995-2000$

$\begin{array}{cc}\text { Adjusted RR* } & 95 \% \mathrm{CI} \\ 1.99 & 1.64-2.41 \\ 1.93 & 1.61-2.31\end{array}$

$\begin{array}{ll}1.56 & 1.12-2.18 \\ 1.63 & 1.17-2.25\end{array}$

0.46

$0.26-0.80$

$0.49 \quad 0.27-0.87$

0.28

$0.10-0.77$

0.30

$0.11-0.82$

0.31

$0.18-0.53$

0.31

$0.18-0.53$ 
Figure 1 - Cusum plot for analysis of time trends in prenatal diagnosis of congenital heart disease*, Paris Registry of Congenital Malformations, 1983 - 2000. The inverted U-shaped curve suggests a monotonically increasing trend in proportion of CHD cases diagnosed over time $(\mathrm{p}<0.001)$

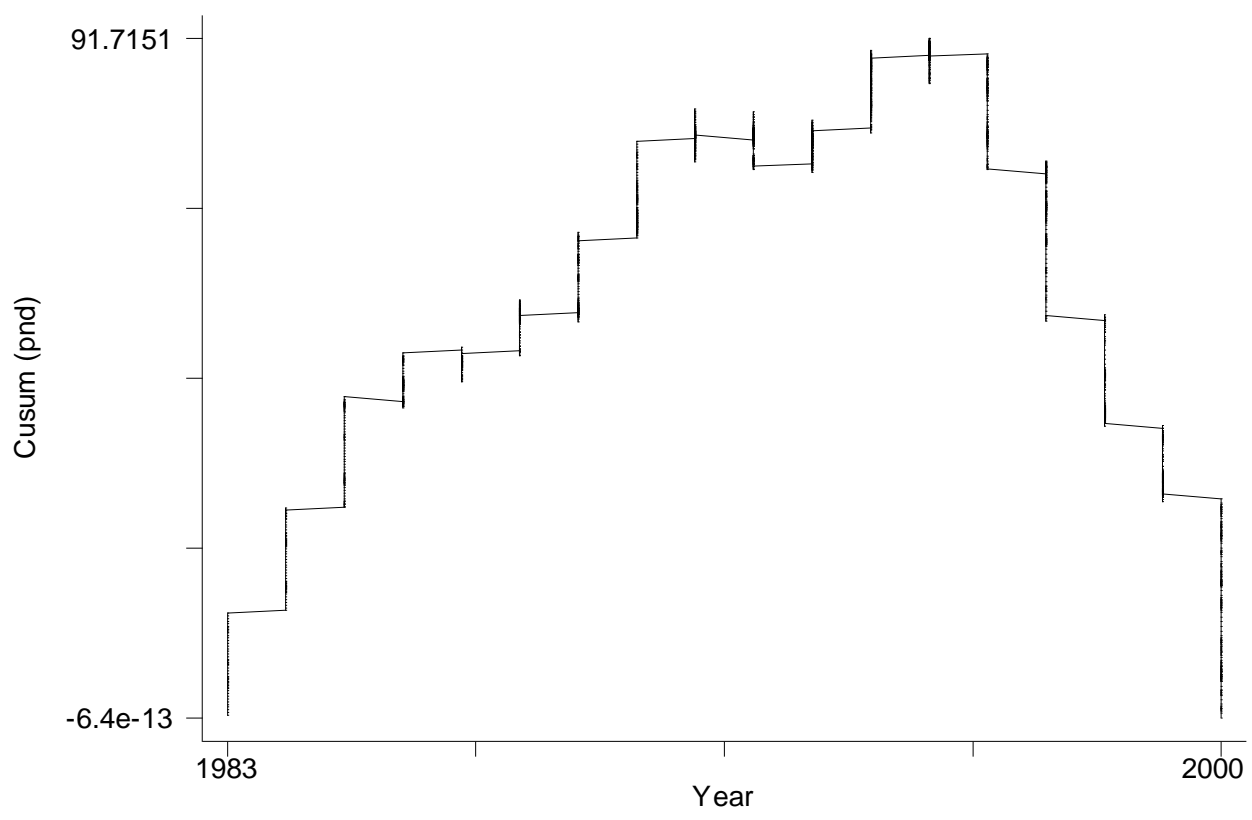

* Cases associated with chromosomal anomalies were excluded. 
Table 3 - Prenatal diagnosis, pregnancy termination, perinatal and early neonatal mortality for selected (isolated) congenital heart anomalies -

Paris Registry of Congenital Malformations, 1983-2000

i) Transposition of Great Arteries

$1983-1988$

Prenatal Diagnosis

Pregnancy Termination

First W eek Mortality

Perinatal Mortality

ii) Hypoplastic Left Heart Syndrome

Prenatal Diagnosis

Pregnancy Termination

First W eek Mortality

Perinatal Mortality
$1983-1988$

$\mathrm{N}$

22

22

18

19
$1989-1994$

$\begin{array}{ccc}\% & 95 \% \mathrm{CI}^{*} & \mathrm{~N} \\ 48.1 & 28.7-68.1 & 40 \\ 7.4 & 0.9-24.3 & 40 \\ 8.3 & 1.0-27.0 & 39 \\ 12.0 & 2.5-31.2 & 40\end{array}$

$1995-2000$

$\begin{array}{ccc}\% & 95 \% \mathrm{CI}^{*} & \mathrm{p}^{\text {क }} \\ 72.5 & 56.1-85.4 & 0.001 \\ 0 & 0-8.8 & 0.62 \\ 2.6 & 0.1-13.5 & 0.04 \\ 5.0 & 0.6-16.9 & 0.02\end{array}$

$1995-2000$

$989-1994$

$\begin{array}{ccc}\% & 95 \% \mathrm{CI}^{*} & \mathrm{p}^{\text {क }} \\ 88.9 & 70.8-97.6 & <0.001 \\ 63.0 & 42.4-80.6 & <0.001 \\ 50.0 & 18.7-81.3 & 0.12 \\ 50.0 & 18.7-81.3 & 0.10\end{array}$


Table 3 - Prenatal diagnosis, pregnancy termination, perinatal and early neonatal mortality for selected (isolated) congenital heart anomalies continued

iii) Coarctation of Aorta

\begin{tabular}{|c|c|c|c|c|c|c|c|c|c|c|}
\hline & \multicolumn{3}{|c|}{$1983-1988$} & \multicolumn{3}{|c|}{$1989-1994$} & \multicolumn{3}{|c|}{$1995-2000$} & \multirow[b]{2}{*}{$p^{q}$} \\
\hline & $\mathrm{N}$ & $\%$ & $95 \% \mathrm{CI}^{*}$ & $\mathrm{~N}$ & $\%$ & $95 \% \mathrm{CI}^{*}$ & $\mathrm{~N}$ & $\%$ & $95 \% \mathrm{CI}^{*}$ & \\
\hline Prenatal Diagnosis & 6 & 0 & $0-45.9$ & 21 & 33.3 & $14.6-57.0$ & 33 & 42.4 & $25.5-60.8$ & 0.03 \\
\hline Pregnancy Termination & 6 & 0 & $0-45.9$ & 21 & 0 & $0-16.1$ & 34 & 0 & $0-10.3$ & - \\
\hline First W eek Mortality & 6 & 0 & $0-45.9$ & 21 & 0 & $0-16.1$ & 34 & 0 & $0-10.3$ & - \\
\hline Perinatal Mortality & 6 & 0 & $0-45.9$ & 21 & 0 & $0-16.1$ & 34 & 0 & $0-10.3$ & - \\
\hline
\end{tabular}

iv) Tetralogy of Fallot

\begin{tabular}{|c|c|c|c|c|c|c|c|c|c|c|}
\hline & \multicolumn{3}{|c|}{$1983-1988$} & \multicolumn{3}{|c|}{$1989-1994$} & \multicolumn{3}{|c|}{$1995-2000$} & \multirow[b]{2}{*}{$\mathrm{p}^{\text {t }}$} \\
\hline & $\mathrm{N}$ & $\%$ & $95 \% \mathrm{CI}^{*}$ & $\mathrm{~N}$ & $\%$ & $95 \% \mathrm{CI}^{*}$ & $\mathrm{~N}$ & $\%$ & $95 \% \mathrm{CI}^{*}$ & \\
\hline Prenatal Diagnosis & 10 & 20.0 & $2.5-55.6$ & 16 & 37.5 & $15.2-64.6$ & 33 & 69.7 & $51.3-84.4$ & 0.005 \\
\hline Pregnancy Termination & 10 & 10.0 & $0.3-44.5$ & 16 & 12.5 & $1.6-38.3$ & 34 & 0 & $0-10.3$ & 0.07 \\
\hline First W eek Mortality & 9 & 0 & $0-33.6$ & 13 & 0 & $0-24.7$ & 33 & 0 & $0-10.6$ & - \\
\hline Perinatal Mortality & 9 & 0 & $0-33.6$ & 14 & 7.1 & $0.2-33.9$ & 34 & 2.9 & $0.1-0.15$ & 0.63 \\
\hline
\end{tabular}

* 95\% binomial exact confidence interval (97.5\% one-sided confidence intervals for cases with zero events).

test of significance for cusum linear annual trend 
Figure 2 - Cusum plot for analysis of time trends in early ( $<1$ week) neonatal mortality of congenital heart disease*, Paris Registry of Congenital Malformations, 1983 - 2000. The U-shaped curve suggests a monotonically decreasing trend in first-week mortality of CHD cases over time $(\mathrm{p}<0.001)$.

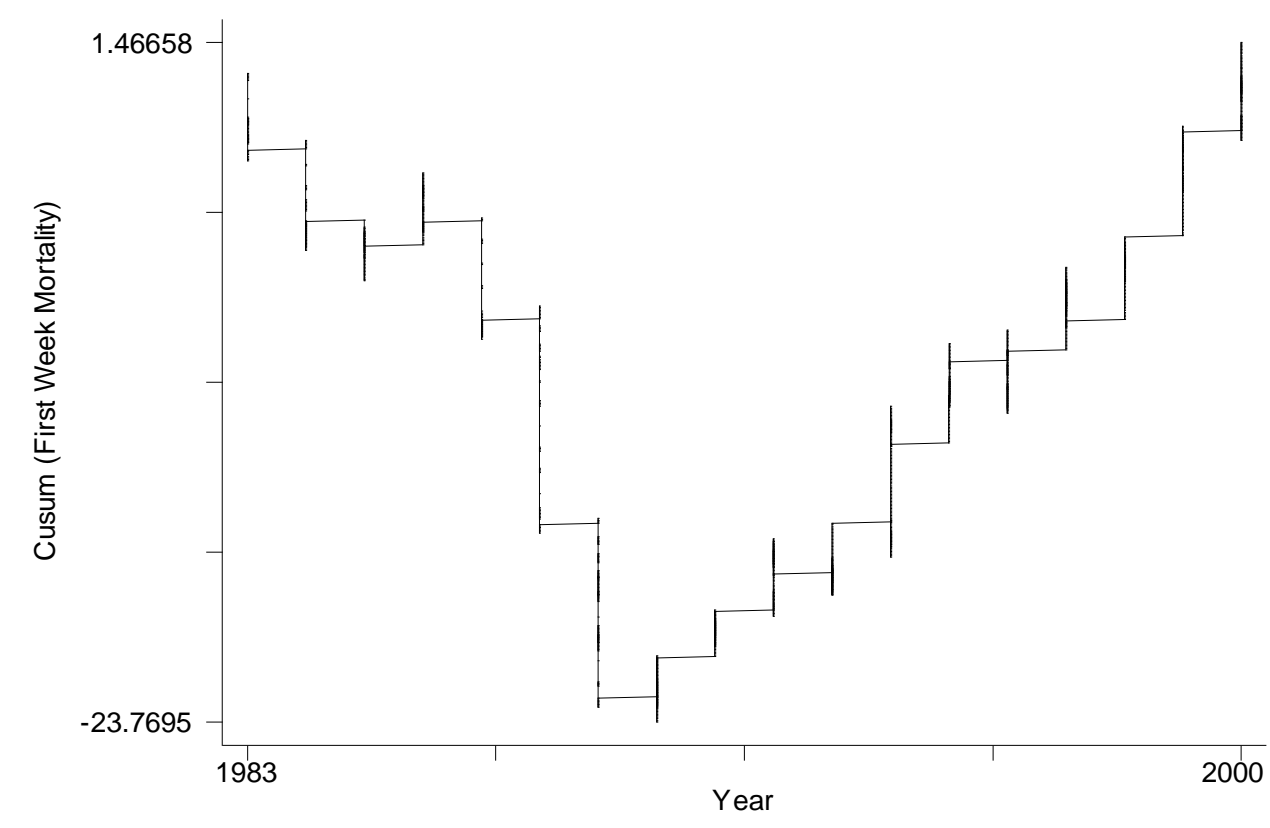

* Cases associated with chromosomal anomalies were excluded. 